\title{
Modeling and Analysis of Truck Mounted Concrete Pump Boom by Virtual Prototyping
}

\author{
Wu Ren, ${ }^{1,2}$ Zhongwei Li, ${ }^{1}$ Yanping Bi, ${ }^{1}$ Shan Zhao, ${ }^{1}$ Bo Peng, ${ }^{3}$ and Liming Zhou ${ }^{1}$ \\ ${ }^{1}$ School of Biomedical Engineering, Xinxiang Medical University, Xinxiang, Henan 453003, China \\ ${ }^{2}$ State Key Laboratory for High Performance Complex Manufacturing, Central South University, Changsha, Hunan 410083, China \\ ${ }^{3}$ Hunan Special Equipment Inspection and Testing Research Institute, Zhangjiajie Branch, Zhangjiajie, Hunan 427000, China
}

Correspondence should be addressed to Wu Ren; renwu88@126.com

Received 4 February 2017; Accepted 7 May 2017; Published 14 June 2017

Academic Editor: Shahram Payandeh

Copyright (C) $2017 \mathrm{Wu}$ Ren et al. This is an open access article distributed under the Creative Commons Attribution License, which permits unrestricted use, distribution, and reproduction in any medium, provided the original work is properly cited.

\begin{abstract}
By far there is lack of research on different working conditions between rigid and flexible dynamics of truck mounted concrete pump booms. First a 3D model has been established by using virtual prototyping technology of a $37 \mathrm{~m}$ long boom in Pro/Engineering software. Then the rigid body simulation model has been built. Next modal superimposition method is adopted to change the 4 rigid body booms into flexible ones. Kinematics law and dynamic characteristics of 4 common working conditions had been studied then. Next tip displacement and the first boom hydraulic cylinder force of the 4 working conditions between rigid and flexible models have been researched. Furthermore the first natural frequencies of the structure have been calculated. The results show that the frequency of the horizontal condition has the lowest of all and the roof condition has the largest of all. Besides the cylinder forces of the flexible model are larger than the corresponding rigid ones because of the flexible boom vibration. Finally an experiment has been done on a boom test rig which proved that the established simulation model is reasonable and the frequency results are correct. All of these provide design reference to mechanical manipulator as well as reducing product development cost of such mechanism.
\end{abstract}

\section{Introduction}

In recently years, $\mathrm{CAD} / \mathrm{CAE} / \mathrm{CAM} / \mathrm{PDM}$ has been further developed including VP (virtual prototype) and PLM (product life-cycle manager) technology [1]. VPD (virtual product development) originated from the Boeing Company in 1990. The use of all digital paperless design made the cost decrease by $25 \%$ and manufacture cycle reduce by $50 \%$. This application technology was called VP (virtual prototyping technology). Virtual prototyping relies on the technology of CAX (such as CAD, CAE, and CAM), DFX (such as design for assembly), and DFM (design for manufacture). Virtual product development has 3 main features: the first one is digitization [2-5]. Next is product life cycle. This is supported by CAD/CAE/CAM/PDM. The last one is network coordination. The development of modern Internet technology makes the network coordination become real. Until now more and more fields are using virtual prototyping technology like vehicle test, train system design, robot control, bridge construction, flexibility manufacturing, hazard identification, and so on. The use of this technology will greatly reduce the development costs and time [6-8]. The relationship between virtual prototyping and traditional CAD/CAE/CAM is shown in Figure 1.

The scientific and innovative contribution of the paper is the establishment of a truck mounted concrete pump boom model considering the boom flexibility and hydraulic actuator equivalent stiffness. In this paper flexible multibody theory has been used to get the dynamics characteristics of different working conditions. Thus the spray control and motion accuracy can be got during the working process. In the previous research the oil elasticity modulus was not considered in the calculating of hydraulic cylinder stiffness. So the flexibility of the cylinder is not accurate. In this paper the cylinder stiffness and boom flexibility are both considered. Thus the accurate boom kinematic and dynamics response could be obtained. The boom model is made up of multisection operating booms, connecting links, hydraulic 


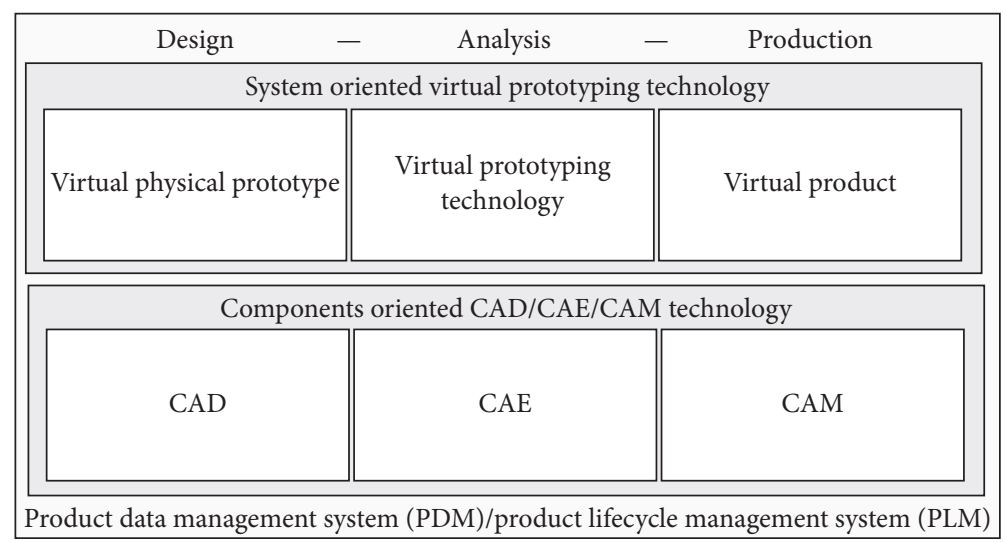

FIGURE 1: Virtual prototyping and traditional CAD/CAE/CAM comparison.

actuator cylinders, and joints. Usually the boom can be simplified as a slim beam and the load is mainly coming from self-weight and pump impact. Thus the boom system stiffness must be large and the self-weight should be light. Frequently boom system dynamics experiments will increase cost and waste time, which can not satisfy production demand. But virtual prototyping technology can solve this problem and reduce the product development cycle $[9,10]$.

Up to now, Slepniov et al. studied production, innovation, and service networks of companies all over the world [1]. They proposed the widening geographical and cognitive gaps between the networks becoming strategically important method in production research. Jiang et al. studied concrete pump outrigger's effect on the safety and stability of the system. The relationship between pipe length and outrigger area is obtained then [11]. Ling et al. did the simulation of a mobile pump boom motion process. The most dangerous working conditions of cylinders had been studied which offered theoretical basis for the optimization design of the hydraulic cylinders [12]. Wang et al. analyzed pouring process of a mobile concrete pump boom. Next they proposed intelligent pouring program of it. In the end the trajectory plan and virtual environments work had been simulated $[13,14]$. Guo et al. established the dynamic equation of flexible booms according to robot theory and language equation which is help for the automatic pouring [15]. Chen and Sun studied the structural optimization of concrete pump displacing boom system by using BP neural network, finite element, and genetic algorithms [16]. Zhang et al. established a truck mounted concrete pump simulation model in ADAMS software and studied the force between the cylinder and link joints which provide design guide for such mechanism [17]. Guo et al. improved the automation pour process by using optimal control method of a mobile concrete pump boom [18]. Jiang built a concrete pump boom virtual prototyping model and carried out the simulation by multibody dynamics and finite element method [19]. Dai et al. used PD control method into concrete pump boom drive. By their study the boom can move in desired angle [20]. Finally they made the boom move with expected rotation angle and tip trajectory. Zhang et al. did control to a flexible boom driven by hydraulic cylinder and had researched the vibration depression of the system $[21,22]$. The safety and diagnostic applied to concrete displacing boom are done by Ambrosio et al. Then Resta et al. established a 1:3 reduced model of a mobile concrete pump. Vibrations suppression, feedforward and feedback actions, disturbance estimator, and modal control were researched. Modal space control method is used to reduce the tip vibration and trajectory control [23-28]. Lenord et al. studied a flexible hydraulic mobile concrete pump truck. Linear and nonlinear models were simulated by damping optimization [29]. In the end a linear model was used to substitute the nonlinear model in order to reduced computational cost. Sun et al. proposed a closedloop monitoring and open-loop control method to suppress the boom vibration [30].

Due to the fact that vibration is very important in the dynamics and kinematics analysis of the concrete pump boom, a rigid-flexible method is adopted in this paper to establish an accurate model of the boom. It is organized as follows. Firstly modal superimposition method is introduced and used. Then rigid and flexible body virtual prototyping models of a truck mounted concrete pump boom have been established. Next the tip displacement and force comparison of the two models in different working conditions are studied. Then natural frequency of the flexible model has been calculated and an experiment has been done on a boom test rig. In the end the conclusion has been discussed.

\section{Modal Superimposition Method}

The multiple degree-of-freedom system with proportional damping motion equation is as follows:

$$
[M]\{\ddot{x}\}+[C]\{\dot{x}\}+[K]\{x\}=\{f(t)\} .
$$

In (1),

$$
[C]=\alpha[M]+\beta[K]
$$

Here in (2), $\alpha$ and $\beta$ are proportional constant. [C] is damping matrix and $[M]$ and $[K]$ are the mass matrix and stiffness 
matrix, respectively. \{\} represents vector and [] represents matrix. By the coordinate transformation, (3) is obtained

$$
\{x\}=\sum_{r=1}^{N} q_{r}\left\{\varphi_{r}\right\}
$$

In (3), $\left\{\varphi_{r}\right\}$ is the $r$-order mode shapes. By replacing (3) with $(1)$,

$$
\begin{gathered}
{[M]\left(\sum_{r=1}^{N} \ddot{q}_{r}\left\{\varphi_{r}\right\}\right)+[C]\left(\sum_{r=1}^{N} \dot{q}_{r}\left\{\varphi_{r}\right\}\right)} \\
+[K]\left(\sum_{r=1}^{N} q_{r}\left\{\varphi_{r}\right\}\right)=\{f(t)\} .
\end{gathered}
$$

Then (4) premultiplied $\left\{\varphi_{s}\right\}^{T}$

$$
\begin{aligned}
& \left\{\varphi_{s}\right\}^{T}[M]\left\{\varphi_{r}\right\}= \begin{cases}0, & r \neq s, \\
m_{s}, & r=s,\end{cases} \\
& \left\{\varphi_{s}\right\}^{T}[K]\left\{\varphi_{r}\right\}= \begin{cases}0, & r \neq s, \\
k_{s}, & r=s .\end{cases}
\end{aligned}
$$

The following equation can be got:

$$
\begin{aligned}
\left\{\varphi_{s}\right\}^{T}[C]\left\{\varphi_{r}\right\} & =\alpha\left\{\varphi_{s}\right\}^{T}[M]\left\{\varphi_{r}\right\}+\beta\left\{\varphi_{s}\right\}^{T}[K]\left\{\varphi_{r}\right\} \\
& = \begin{cases}0, & r \neq s, \\
\alpha m_{s}+\beta k_{s}=c_{s}, & r=s .\end{cases}
\end{aligned}
$$

Here $m_{s}, k_{s}, c_{s}$ are the $s$-order modal mass, modal stiffness, and modal damping coefficient. Next (7) can be obtained

$$
m_{s} \ddot{q}_{s}+c_{s} \dot{q}_{s}+k_{s} q_{s}=\left\{\varphi_{s}\right\}^{T}\{f(t)\}
$$

In (7) $q_{s}$ is the $s$-order modal coordinates. Assuming that $\{f(t)\}=\{F\} e^{j \omega t}$ and $q_{s}=Q_{s} e^{j \omega t}$ by replacing them in (7) we can get

$$
\begin{aligned}
\left(-\omega^{2} m_{s}+j \omega c_{s}+k_{s}\right) Q_{s} e^{j \omega t} & =\left\{\varphi_{s}\right\}^{T}\{F\} e^{j \omega t}, \\
Q_{s} & =\frac{\left\{\varphi_{s}\right\}^{T}\{F\}}{-\omega^{2} m_{s}+j \omega c_{s}+k_{s}} .
\end{aligned}
$$

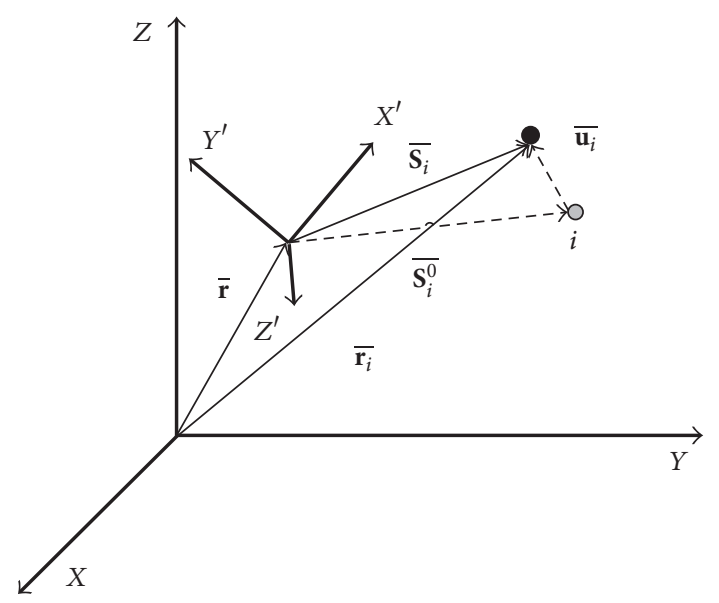

FIGURE 2: Flexible body coordinate system.

In (8) and (9), $Q_{s}$ modal coordinates vector. Next the displacement response can be written as

$$
\begin{aligned}
\{x\} & =\left\{\begin{array}{c}
X_{1} \\
X_{2} \\
\vdots \\
X_{N}
\end{array}\right\} e^{j \omega t}=\sum_{r=1}^{N} q_{r}\left\{\varphi_{r}\right\}=\sum_{r=1}^{N} Q_{r}\left\{\varphi_{r}\right\} e^{j \omega t}, \\
\{X\} & =\left\{\begin{array}{c}
X_{1} \\
X_{2} \\
\vdots \\
X_{N}
\end{array}\right\}=\sum_{r=1}^{N} Q_{r}\left\{\varphi_{r}\right\}=\sum_{r=1}^{N} \frac{\left\{\varphi_{r}\right\}^{T}\{F\}\left\{\varphi_{r}\right\}}{-j \omega c_{r}+k_{r}} \\
& =\sum_{r=1}^{N} \frac{\left\{\varphi_{r}\right\}\left\{\varphi_{r}\right\}^{T}}{-\omega^{2} m_{r}+j \omega c_{r}+k_{r}}\{F\} .
\end{aligned}
$$

Modal superimposition method is based on FMBD (finite element multibody dynamics) and obtains flexible body dynamic stress, strain, and deformation through finite element analysis. Its calculation speed is fast and can calculate large-scale flexible bodies. So it is suitable for the flexibility analysis of construction machinery. A point $i$ on the flexible body's three-dimensional coordinate can expressed as in Figure 2

$$
\overline{\mathbf{r}}_{i}=\overline{\mathbf{r}}+\mathbf{A} \overline{\mathbf{S}}_{i} n=\overline{\mathbf{r}}+\mathbf{A}\left(\overline{\mathbf{S}}_{i}^{0} n+\overline{\mathbf{u}}_{i} n\right) .
$$

In (11), $\mathbf{A}$ is the direction cosine matrix, $\overline{\mathbf{S}}_{i}^{0}$ is the point $i$ not deformed vector, $\overline{\mathbf{u}}_{i}$ is the relative deformation, and $i$ is the translational and rotational modal matrix as shown in

$$
\Psi^{i}=\left[\Psi_{t}^{i T}, \Psi_{r}^{i T}\right] .
$$

The modal coordinate of $\overline{\mathbf{u}}_{i}$ is shown as

$$
\mathbf{u}_{i}^{\prime}=\Psi_{t}^{i^{\prime}} \overline{\mathbf{a}} .
$$


Figure 3: Boom system CAD model.

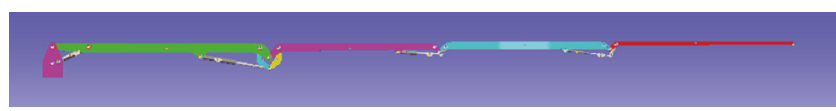

Figure 4: Boom system rigid model.

In (13), $\overline{\mathbf{a}}$ is the generalized coordinates of deformation; from (11) and (13), the following equation can be got:

$$
\overline{\mathbf{r}}_{i}=\overline{\mathbf{r}}+\mathbf{A}\left(\overline{\mathbf{S}}_{i}^{0^{\prime}}+\Psi_{t}^{i^{\prime}} \overline{\mathbf{a}}\right) .
$$

The displacement of the flexible body is shown as (15). According to modal information $\Psi$ the corresponding velocity and acceleration equation of the flexible body can be obtained either

$$
[\mathbf{u}]=\sum a_{i}[\boldsymbol{\varphi}]_{i} .
$$

In (15), [ $\mathbf{u}]$ is the sum of all nodes displacement; $a_{i}$ is the modal factor; $[\varphi]_{i}$ is the component modal. The flexible body deformation can be got by adding the nodes displacement.

The velocity and acceleration of point $i$ can be obtained by derivation for (14) which is shown in

$$
\begin{aligned}
& \overline{\dot{\mathbf{r}}}_{i}=\overline{\dot{\mathbf{r}}}+\dot{\mathbf{A}}\left(\overline{\mathbf{S}}_{i}^{0^{\prime}}+\Psi_{t}^{i^{\prime}} \overline{\mathbf{a}}\right)+\mathbf{A} \Psi_{t}^{i^{\prime}} \overline{\dot{\mathbf{a}}}, \\
& \overline{\ddot{\mathbf{r}}}_{i}=\overline{\mathbf{r}}+\ddot{\mathbf{A}}\left(\overline{\mathbf{S}}_{i}^{0^{\prime}}+\Psi_{t}^{i^{\prime}} \overline{\mathbf{a}}\right)+2 \dot{\mathbf{A}} \Psi_{t}^{i^{\prime}} \overline{\dot{\mathbf{a}}}+\mathbf{A} \Psi_{t}^{i}{ }^{\prime} \overline{\ddot{\mathbf{a}}}
\end{aligned}
$$

\section{Truck Mounted Concrete Pump Boom Modeling by Virtual Prototyping Technology}

The established 3D model of a truck mounted concrete pump boom is shown in Figure 3. The system is built up by 4 booms, several links, hydraulic actuators, joints, and other components.

After importing the CAD model into RecurDyn software the virtual prototyping model with appropriate constraints is obtained too. RecurDyn is multibody system software of FunctionBay, Inc. It is an innovative Multibody Dynamics offering multibody dynamic capabilities with an integrated powerful FEM extension. With the finite element method combined with MFBD (Multiflexible Body Dynamics) the mechanical system simulation can provide more and more precise dynamic motion results including stress analysis for engineers. The flexible body contacts and nonlinear deformations can be solved in it too. So it is very useful in dealing with the long flexible boom here. The built rigid model is shown as Figure 4. Due to the fact that the booms are flexible largescale motion components, the flexible influence should not
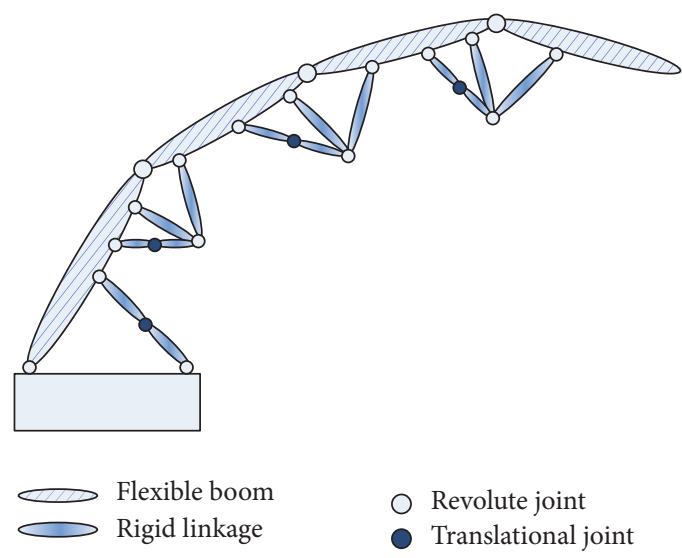

FIGURE 5: Flexible multibody boom topology sketch.

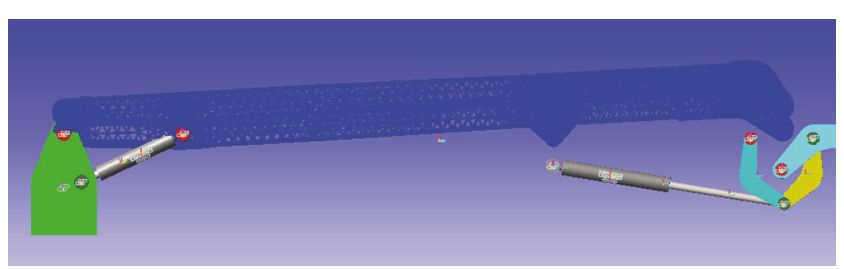

Figure 6: The first boom modal reduction flexible body.

TABLE 1: Parameters of boom system.

\begin{tabular}{lcc}
\hline & Component & Number \\
\hline Flexible body & Boom & 4 \\
Rigid body & Linkage & 14 \\
Joint & Bearing, linkage, boom & 21 \\
Translational joint & Hydraulic cylinder piston & 4 \\
Spring damper & Hydraulic cylinder & 4 \\
\hline
\end{tabular}

TABLE 2: Main parameters of each boom.

\begin{tabular}{lcccc}
\hline Boom & 1 & 2 & 3 & 4 \\
\hline Length $(\mathrm{mm})$ & 3750 & 2830 & 2870 & 3200 \\
Mass $(\mathrm{kg})$ & 88 & 38 & 32 & 18 \\
\hline
\end{tabular}

be neglected. Then a flexible body truck mounted concrete pump boom model is established as shown in Figure 5. In it the four booms are modal flexible bodies calculated by finite element software ANSYS. The first boom flexible body is shown in Figure 6. The other three booms are similar to the first one. By importing them into RecurDyn the concrete pump boom flexible model has been built with constraints consistent with rigid body model. The control scheme of the large scale is used with PID regulator. And the model parameters are as in Table 1. The element mass and length are in Table 2.

\section{Simulation and Experiment}

4.1. Simulation Parameters. The general working conditions of concrete pump boom are horizontal condition, ground 


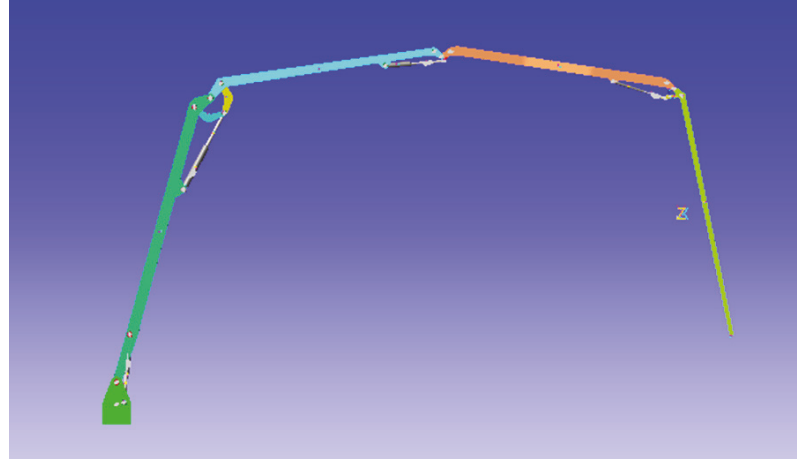

FIGURE 7: Ground condition.

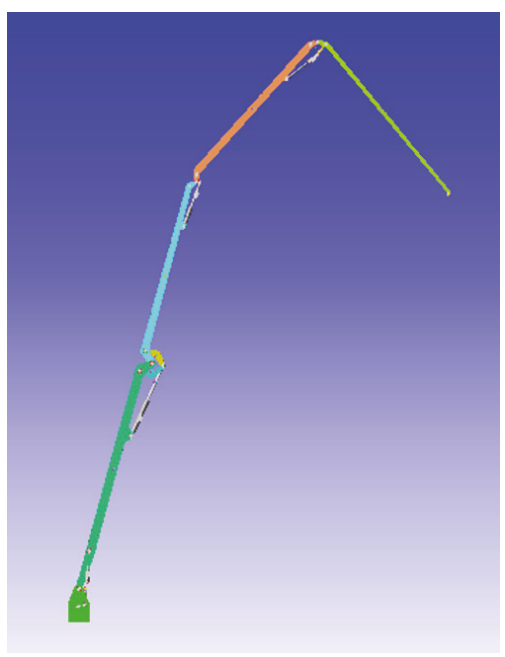

FIgURE 8: Wall condition.

TABLE 3: Each boom angle of working posture.

\begin{tabular}{lcccc}
\hline Posture & Boom 1 & Boom 2 & Boom 3 & Boom 4 \\
\hline Horizontal & $0^{\circ}$ & $0^{\circ}$ & $0^{\circ}$ & $0^{\circ}$ \\
Ground & $75^{\circ}$ & $15^{\circ}$ & $-15^{\circ}$ & $-75^{\circ}$ \\
Wall & $75^{\circ}$ & $45^{\circ}$ & $0^{\circ}$ & $-45^{\circ}$ \\
Roof & $75^{\circ}$ & $75^{\circ}$ & $45^{\circ}$ & $-45^{\circ}$ \\
\hline
\end{tabular}

condition, wall condition, and roof condition. The first condition is simulating the long distance. Because this condition is the most dangerous working condition, the stress value and flexible effect are the largest of all. Next the second condition is used in the ground working process. And the third working condition is used in the wet concrete pumping of lower floors. The last simulation is about the upper floors. So these four simulations are typical working conditions of concrete pump boom. In the built model the tip displacements and the first hydraulic cylinder force are studied. The four simulation postures angles of the two models are shown in Figures 4, 7, 8, and 9. Table 3 is the posture angle of each working condition.

In order to get the truck mounted concrete pump boom kinematic rule and vibration characteristic, the motion simulation results of the above working conditions are studied.

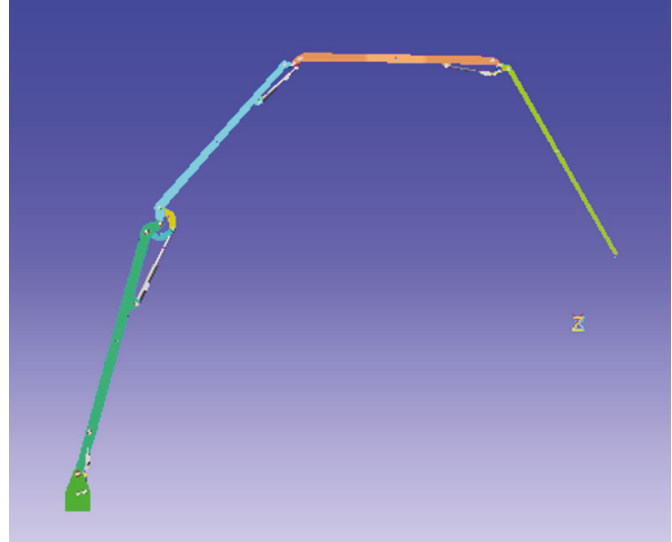

FIgURE 9: Roof condition.

Each boom is driven by its hydraulic actuator. The actuators motion is in Table 4 . In every condition the first boom gets the motion at first. Then the other three booms successively move. During the simulation each segment mass, stiffness and oil stiffness are considered also. The time history of each cylinder during different working conditions is as in Figure 10. Because in the horizontal condition only the 1st cylinder has motion, the time history of the other three cylinders is zero.

4.2. Tip Displacement Simulation Results. The tip displacements of the rigid and flexible model between the four conditions are shown in Figure 11.

In Figure 11(a) we can find when the hydraulic cylinder motion stops the model immediately stops and there is no vibration of the rigid model. However the flexible model vibration will occur and last for a time due to the flexible deformation after the motion stops. It does downward movement when the motion occurs because of the gravity and then move upward. After several seconds the vibration disappears due to the structure damping. The other three working conditions seen in Figures 11(b), 11(c), and 11(d) are similar to horizontal one. But the first condition has the maximum vibration amplitude. This demonstrates that the first condition has the most flexibility during the four pouring process.

4.3. Hydraulic Cylinder Force Simulation Results. Figure 12 is the first hydraulic cylinder force between rigid model and flexible model. It can be seen that the corresponding flexible model force is larger than the rigid model at a certain degree. Along with the booms movement the force also increases or decreases periodically. After the motion termination the forces tend to constant value in the end. The maximum force of all the conditions of the flexible model is $72 \mathrm{kN}$ in the horizontal working condition, which is $30 \mathrm{kN}$ larger than the corresponding rigid model. This verifies that horizontal condition is the most dangerous of all. Therefore in design of similar large-scale motion manipulator the mechanical flexible influence should be considered. 


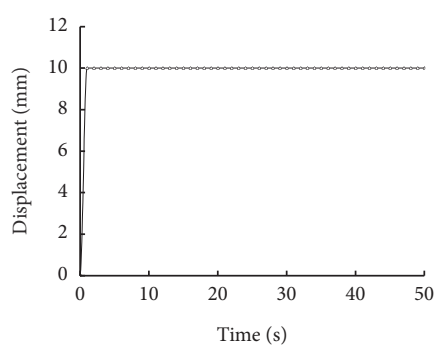

(a1)

(a)

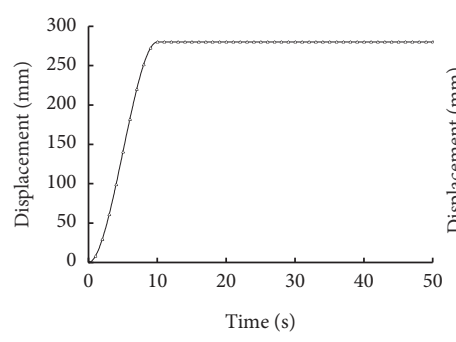

(b1)

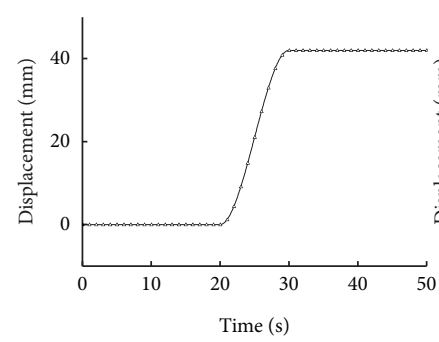

(c1)

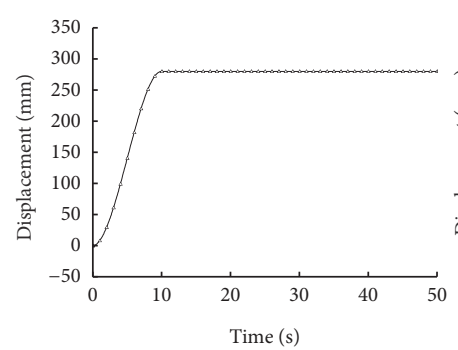

(d1)

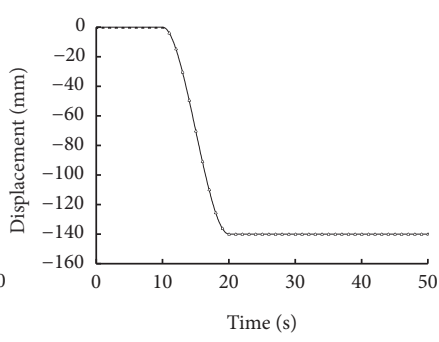

(b2)

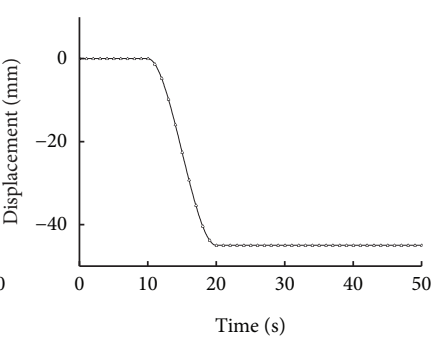

(c2)

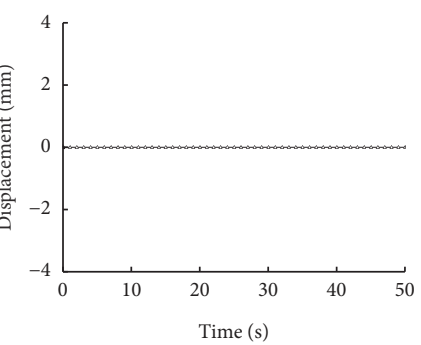

(d2)

(b)

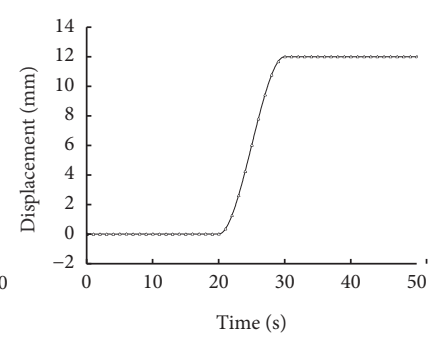

(b3)

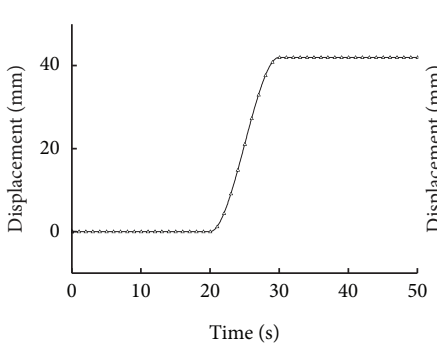

(c3)

c)

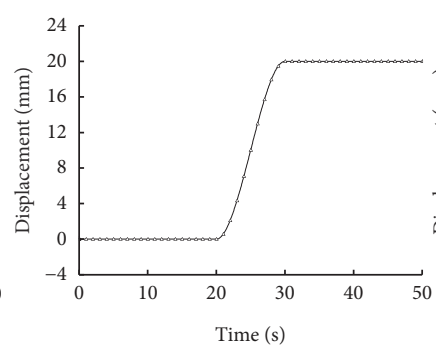

(d3)

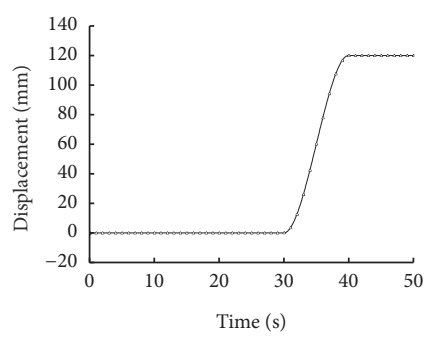

(b4)

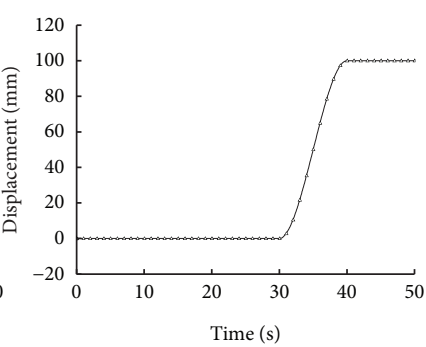

(c4)

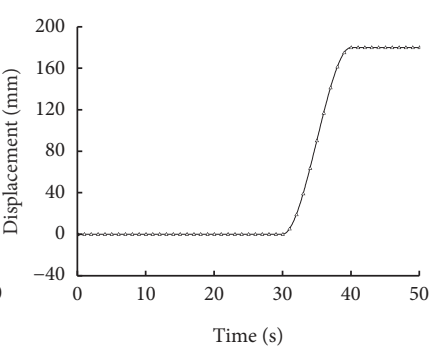

(d4)

(d)

FIGURE 10: Time history of each cylinder during different working conditions ((a) horizontal condition; (b) ground condition; (c) wall condition; (d) roof condition; 1: cylinder 1; 2: cylinder 2; 3: cylinder 3; 4: cylinder 4).

TABLE 4: The cylinder motion function.

\begin{tabular}{lcccc}
\hline & First cylinder & Second cylinder & Third cylinder & Forth cylinder \\
\hline Horizontal & Step (time, 0, 0, 1, 10) & 0 & 0 & 0 \\
Ground & Step (time, 0, 0, 10, 280) & Step (time, 10, 0, 20, -140) & Step (time, 20, 0, 30, 12) & Step (time, 30, 0, 40, 120) \\
Wall & Step (time, 0, 0, 10, 280) & Step (time, 10, 0, 20, -45) & Step (time, 20, 0, 30, 42) & Step (time, 30, 0, 40, 100) \\
Roof & Step (time, 0, 0, 10, 280) & Step (time, 10, 0, 20, 0) & Step (time, 20, 0, 30, 20) & Step (time, 30, 0, 40, 180) \\
\hline
\end{tabular}




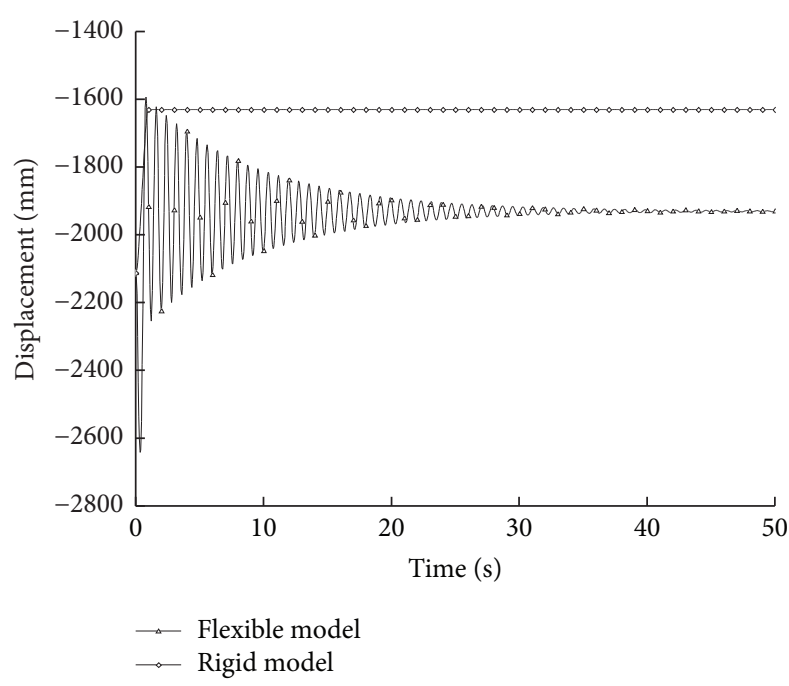

(a)

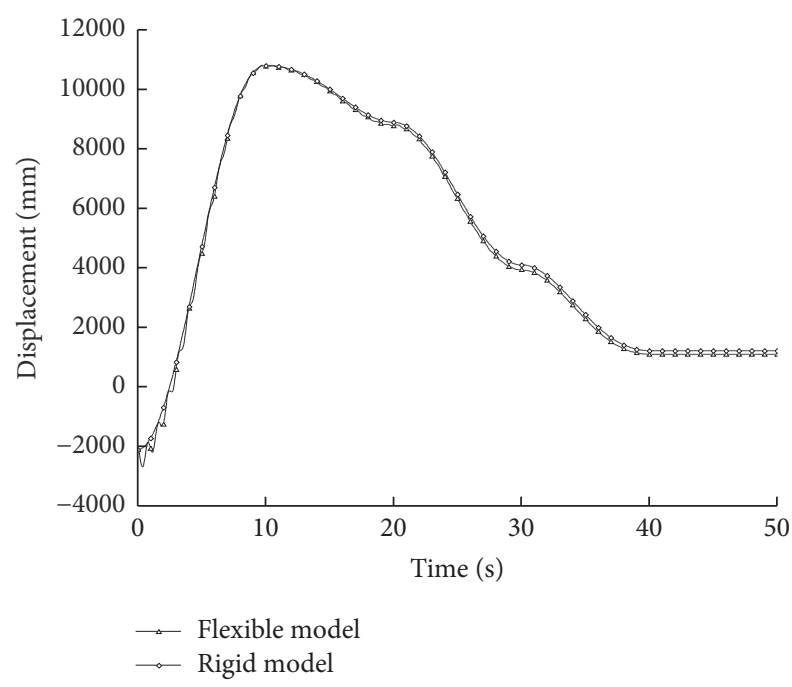

(c)

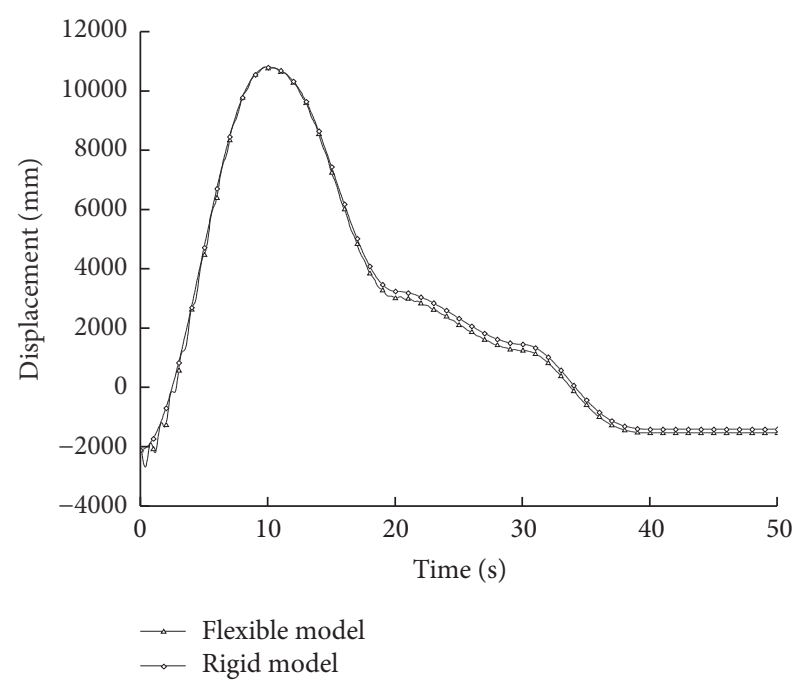

(b)

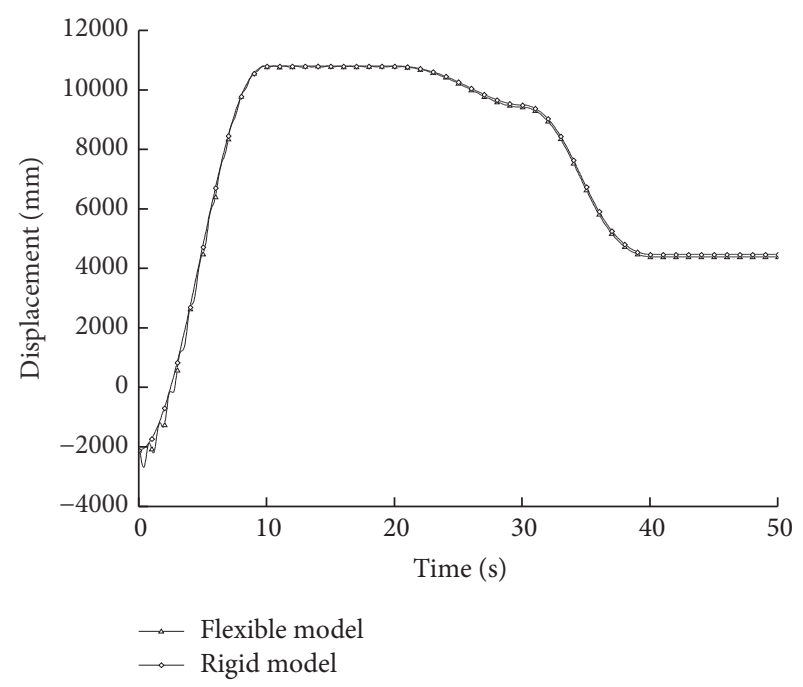

(d)

FIGURE 11: Tip displacements between rigid model and flexible model. (a) Horizontal condition; (b) ground condition; (c) wall condition; (d) roof condition.

4.4. Natural Frequency Analysis and Experiment. In this section, the first natural frequencies in the vertical plane have been studied. In order to verify that the simulation is correct a test has done on a boom test rig as shown in Figure 13. The test rig parameters are the same as simulation ones. The material is Q345B and is $13.46 \mathrm{~m}$ long. It mounts on a steel base with screw thread legs and casters. The thread legs are used to bear gravity and motion dynamics. The required instrument also includes DEWETRON dynamic data collection equipment, which has 24 channels, 8 accelerate channels, 2 CAN modules, and a CPU. Accelerometer strain sensor is also needed. The boom test rig is as shown in Figure 13.

By analyzing the obtained acceleration signal of the boom tip the modal flexible body natural frequency can be got by FFT transform. The corresponding frequency of simulation models is also given in Table 5.
TABLE 5: The first natural frequency of vertical posture between simulation and test.

\begin{tabular}{lcccc}
\hline & Horizontal & Ground & Wall & Roof \\
\hline Simulation value & 0.872 & 0.920 & 0.903 & 1.184 \\
Test value & 0.812 & 0.829 & 0.861 & 1.040 \\
\hline
\end{tabular}

Figure 14 shows the first 10-second tip acceleration comparison of simulation and experiment in horizontal working condition.

According to Table 5, the obtained simulation results of the four working conditions are larger than the measured ones. This is because only the four booms are equivalent to flexible body and the other connecting links and hydraulic cylinder are still considered as rigid body. This increases the 


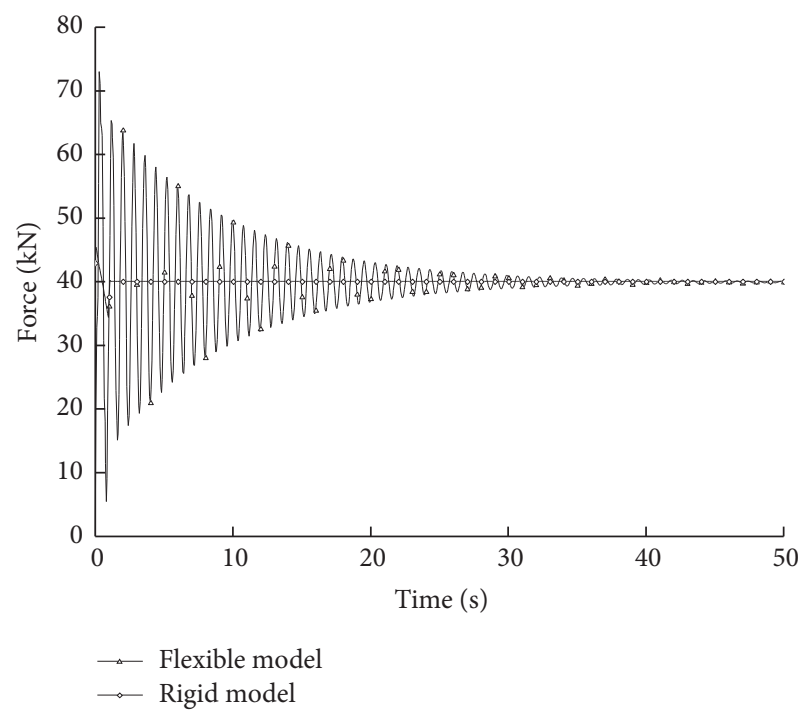

(a)

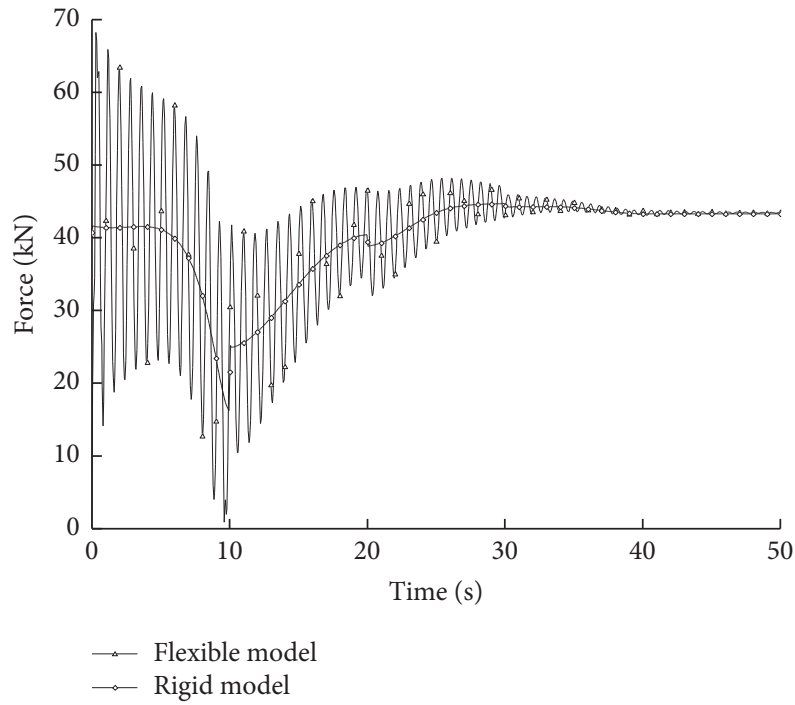

(c)

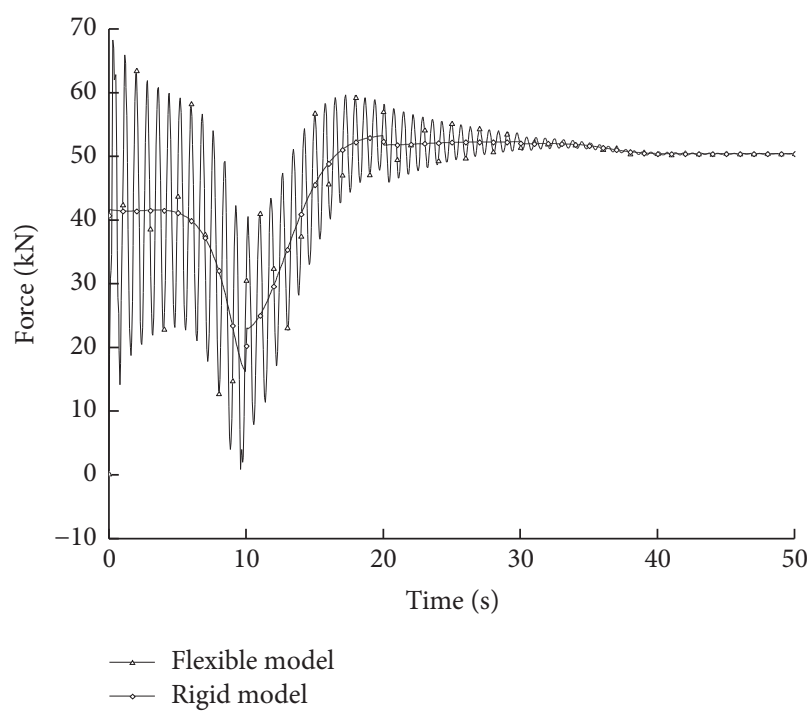

(b)

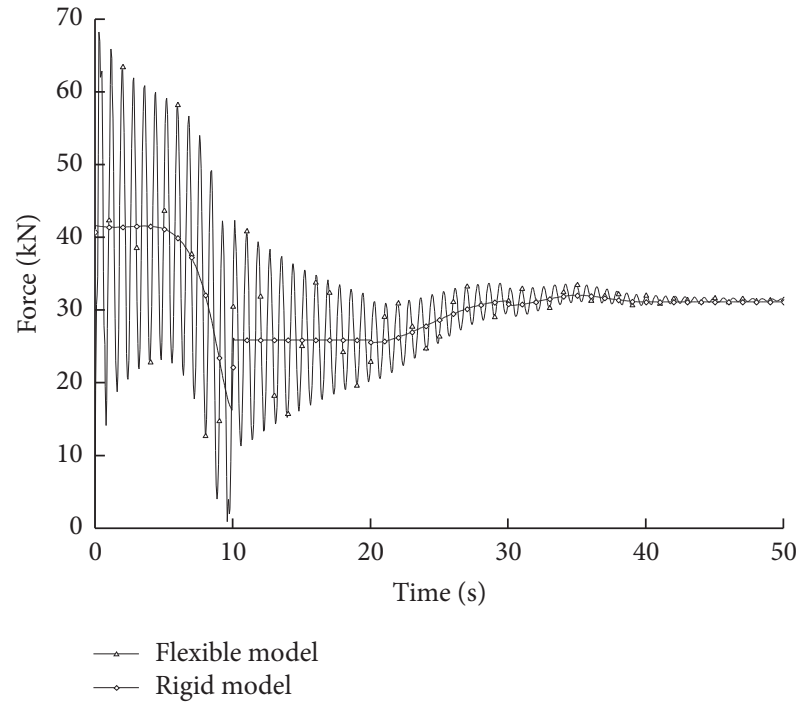

(d)

FIGURE 12: The first hydraulic cylinder force between rigid model and flexible model. (a) horizontal condition; (b) ground condition; (c) wall condition; (d) roof condition.

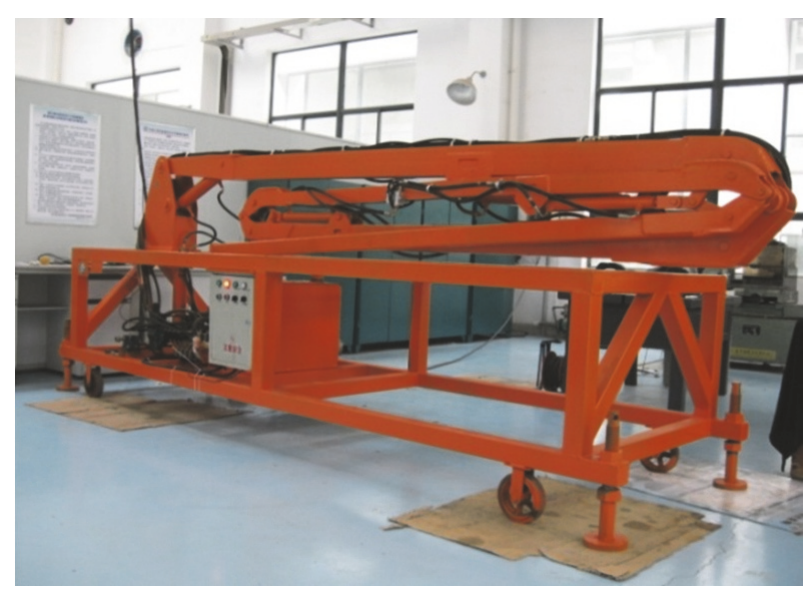

FIGURE 13: Boom test rig. 


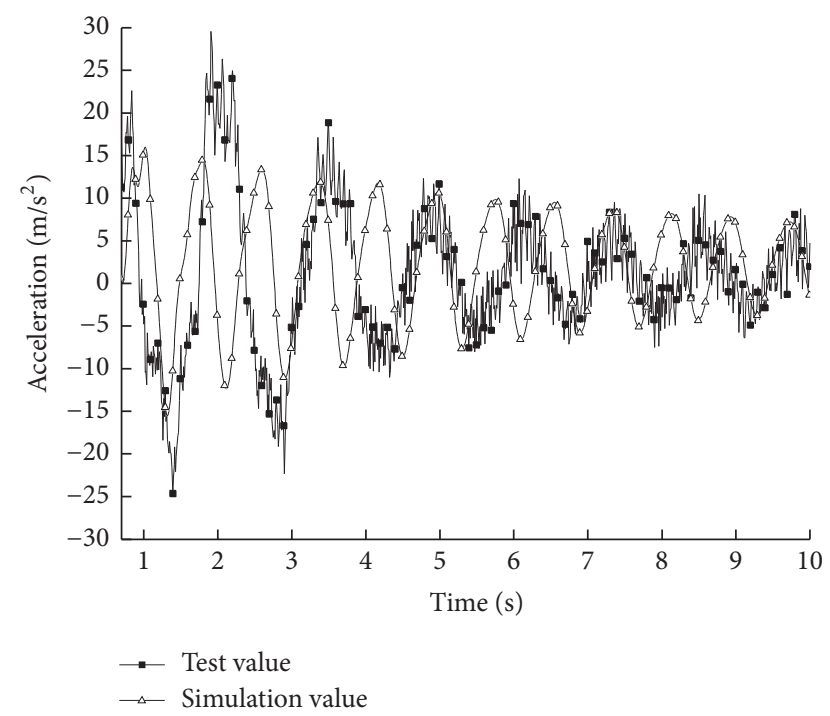

FIGURE 14: Acceleration signal of simulation and experiment ones.

natural frequency to a certain extent. If the other components are flexible the natural frequency will close to the test value.

\section{Conclusion}

The virtual prototyping technology is adopted to establish the rigid and flexible models of a large-scale motion truck mounted concrete pump boom in this study. In the flexible model modal superimposition method has been adopted. By comparing the two models, the tip displacement and cylinder force, the kinematic and dynamic characteristics have been studied. The flexible model tip displacements of the four working conditions are all larger than the rigid model. This is because the flexible model has vibration during the motion. The cylinder forces are all increasing largely in all the conditions and become nearly 2 times larger than the rigid model. The results show that the flexible analysis is necessary. Finally an experiment has been done on a test rig which proves that the proposed method is reasonable in this paper. The first natural frequencies in the vertical plane are researched then. The horizontal condition has the lowest frequency and the roof condition has the largest one. And the results are in good agreement too. All of these provide vibration control reference and fatigue analysis of such lowfrequency manipulators. The virtual prototyping technology is convenient in reducing production design cost and time for engineers.

\section{Conflicts of Interest}

The authors declare that there are no conflicts of interest regarding the publication of this paper.

\section{Acknowledgments}

This work was supported by study on "Human Machine Dynamic Characteristics of Multi Degree of Freedom
Rehabilitation Displacement Device" (172102310542), "MultiDOF Rehabilitation Patient Transfer Device Dynamics Characteristic and Human-Machine Safety Comfort Research" (505140), "Human Comfort Study by Elevator Transportation Based on Multi-Body Dynamics" (no. 2015KYJH33), and the Natural Science Foundation of Henan Province (2014GGJS-096 and 152102310357); abnormal shear stress mediated expression of pcsk9 in atherosclerotic plaque cells (152102210339); effect of mechanical factors on protein expression in atherosclerotic plaque cells (15a180056).

\section{References}

[1] D. Slepniov, B. V. Wæhrens, and J. Johansen, "Production, innovation and service networks: complex interplay, evolution and coordination," International Journal of Product Development, vol. 17, no. 3-4, pp. 189-203, 2012.

[2] M. Karkee, B. L. Steward, A. G. Kelkar, and Z. T. Kemp II, "Modeling and real-time simulation architectures for virtual prototyping of off-road vehicles," Virtual Reality, vol. 15, no. 1, pp. 83-96, 2011.

[3] H. Li, N. K. Y. Chan, T. Huang, M. Skitmore, and J. Yang, "Virtual prototyping for planning bridge construction," Automation in Construction, vol. 27, pp. 1-10, 2012.

[4] C. K. Chun, H. Li, and M. Skitmore, "The use of virtual prototyping for hazard identification in the early design stage," Construction Innovation, vol. 12, no. 1, pp. 29-42, 2012.

[5] M. I. C. Dede, "Virtual prototyping for robot controllers," International Journal of Design Engineering, vol. 3, no. 3, pp. 276-288, 2010.

[6] M. Datar, I. Stanciulescu, and D. Negrut, "A co-simulation environment for high-fidelity virtual prototyping of vehicle systems," International Journal of Vehicle Systems Modelling and Testing, vol. 7, no. 1, pp. 54-72, 2012.

[7] A. Shahin and N. Rostamian, "Concurrent engineering and manufacturing flexibility: an integrated model," International Journal of Productivity and Quality Management, vol. 12, no. 2, pp. 121-140, 2013.

[8] K. H. Han, S. M. Bae, S. H. Choi, and G. Lee, "Parameterdriven rapid virtual prototyping of flexible manufacturing system," International Journal of Mathematics and Computers in Simulation, vol. 6, no. 4, pp. 387-396, 2012.

[9] M. H. Abidi, A. M. Tamimi, A. M. Ahmari, and E. S. Nasr, "Assessment and comparison of immersive virtual assembly training system," International Journal of Rapid Manufacturing, vol. 3, no. 4, pp. 266-283, 2013.

[10] L. Debao and L. Qiuhai, Analysis of Experiments in Engineering Vibration, Tsinghua University Press, Beijing, China, 2004.

[11] Y. Jiang, J. Li, and G. Zhang, "The effect of outrigger structure design on the stability of truck concrete pump," Construction Machinery, vol. 25, no. 3, pp. 67-68, 2005.

[12] Z. Ling, P. Fu, H. Liu et al., "Simulate research on the amplitude changing mechanism arm support of concrete pump vehicle," Machinery Design and Manufacture, vol. 31, no. 5, pp. 101-103, 2011.

[13] T. Wang, G. Wang, K. Liu, and S. Zhou, "Simulation control of concrete pump truck boom based on PSO and gravity compensation," in Proceedings of the 2nd International Symposium on Intelligent Information Technology Application (IITA '08), pp. 960-963, Shanghai, China, December 2008. 
[14] Z.-J. Gou, "The simulation of harmonic vibration response based on the rigid and flexible boom system of the ttruckmounted concrete pump," in Proceedings of the International Conference on Electronic and Mechanical Engineering and Information Technology (EMEIT '11), pp. 2404-2407, Harbin, China, August 2011.

[15] D.-M. Guo, K. Liu, D.-L. Xu, and J. Liu, "Effect of the vibration coupling pumped concrete fluid with conveying pipes on concrete pump truck," Journal of Northeastern University, vol. 31, no. 1, pp. 99-102, 2010.

[16] K. Chen and G. Sun, "Intelligent optimun design of boom frame of concrete pumping vehicle," Journal of Wuhan University of Technology, vol. 27, no. 2, pp. 244-246, 2003.

[17] S. Zhang, M. Feng, and P. Zhang, "Boom kinematic analysis of concrete pump truck based on ADAMS," Construction Machinery, vol. 21, no. 21, pp. 123-125, 2001.

[18] L. Guo, G. Zhang, and J. Li, "Approach to robotization of concrete boom truck for construction," Machine Design and Manufacturing Engineering, vol. 29, no. 2, pp. 6-8, 2000.

[19] T. Jiang, Application study of virtual prototuping technology on concrete pump truck [Ph.D. thesis], Nanjing University of Technology, Nanjing, China, 2005.

[20] L. Dai, J. Wang, Y. Liu et al., "PD control of swiveling jib system of concrete delivery truck," Journal of Northeastern University, vol. 30, no. 11, pp. 1645-1648, 2009.

[21] C.-Y. Zhang and G.-C. Bai, "Extremum response surface method of reliability analysis on two-link flexible robot manipulator," Journal of Central South University of Technology, vol. 19, no. 1, pp. 101-107, 2012.

[22] G. Li and M. Wu, "Modeling and controlling of a flexible hydraulic manipulator," Journal of Central South University of Technology, vol. 12, no. 5, pp. 578-583, 2005.

[23] P. Ambrosio, G. Cazzulani, F. Resta, and F. Ripamonti, "An optimal vibration control logic for minimising fatigue damage in flexible structures," Journal of Sound and Vibration, vol. 333, no. 5, pp. 1269-1280, 2014.

[24] G. Cazzulani, S. Moschini, F. Resta, and F. Ripamonti, "A diagnostic logic for preventing structural failure in concrete displacing booms," Automation in Construction, vol. 35, pp. 499506, 2013.

[25] G. Cazzulani, C. Ghielmetti, H. Giberti, F. Resta, and F. Ripamonti, "A test rig and numerical model for investigating truckmounted concrete pumps," Automation in Construction, vol. 20, no. 8, pp. 1133-1142, 2011.

[26] G. Bagordo, G. Cazzulani, F. Resta, and F. Ripamonti, "A modal disturbance estimator for vibration suppression in nonlinear flexible structures," Journal of Sound and Vibration, vol. 330, no. 25, pp. 6061-6069, 2011.

[27] G. Cazzulani, F. Resta, and F. Ripamonti, "A feedback and feedforward vibration control for a concrete placing boom," Journal of Vibration and Acoustics, vol. 133, no. 5, Article ID 051002, pp. 1-8, 2011.

[28] F. Resta, F. Ripamonti, G. Cazzulani, and M. Ferrari, "Independent modal control for nonlinear flexible structures: an experimental test rig," Journal of Sound and Vibration, vol. 329, no. 8, pp. 961-972, 2010.

[29] O. Lenord, S. Fang, D. Franitza, and M. Miller, "Numerical linearisation method to efficiently optimise the oscillation damping of an interdisciplinary system model," Multibody System Dynamics, vol. 10, no. 2, pp. 201-217, 2003.
[30] X. Sun, H. Ye, and S. Fei, "A closed-loop detection and openloop control strategy for booms of truck-mounted concrete pump," Automation in Construction, vol. 31, pp. 265-273, 2013. 


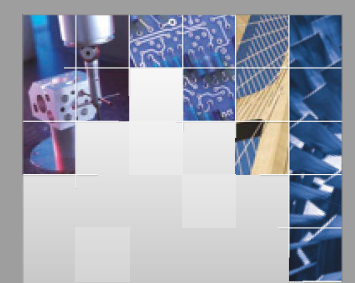

\section{Enfincering}
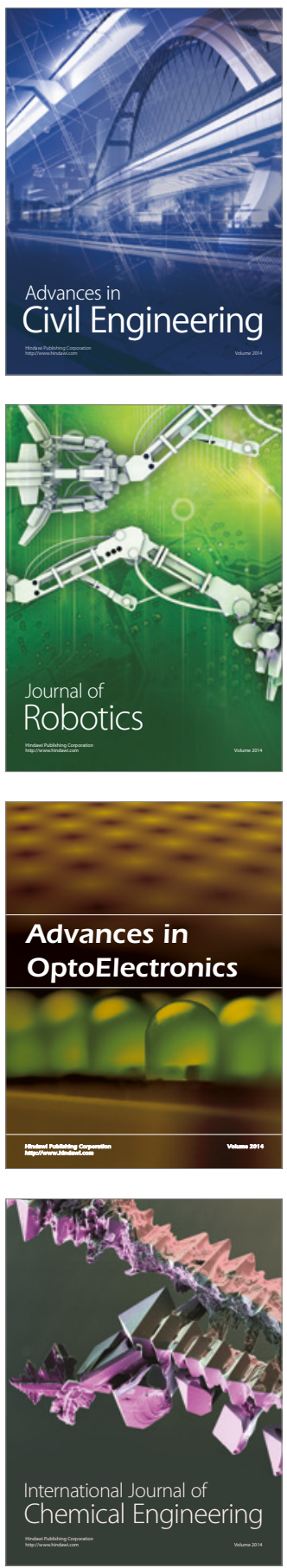

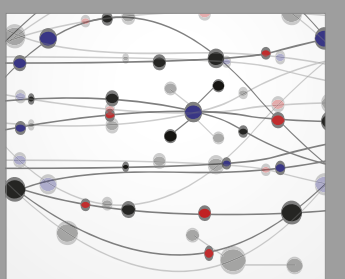

The Scientific World Journal

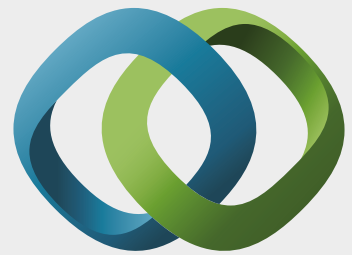

\section{Hindawi}

Submit your manuscripts at

https://www.hindawi.com
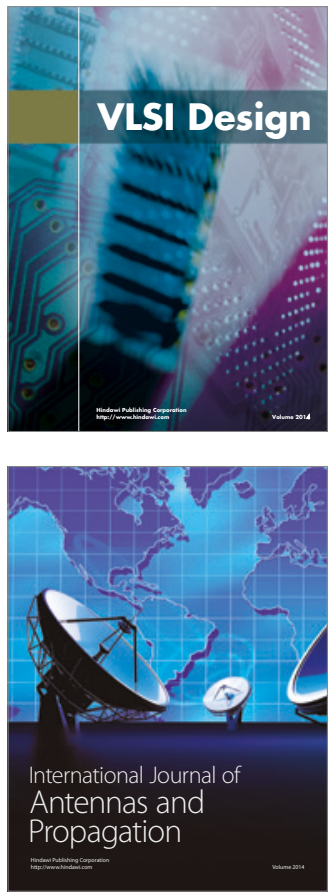

\section{Rotating}

Machinery
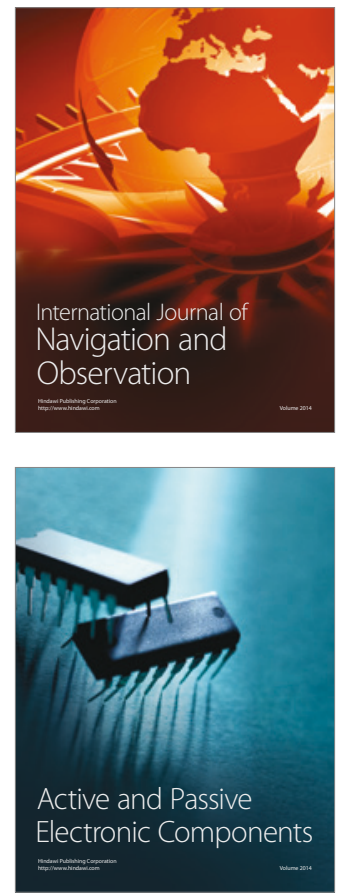
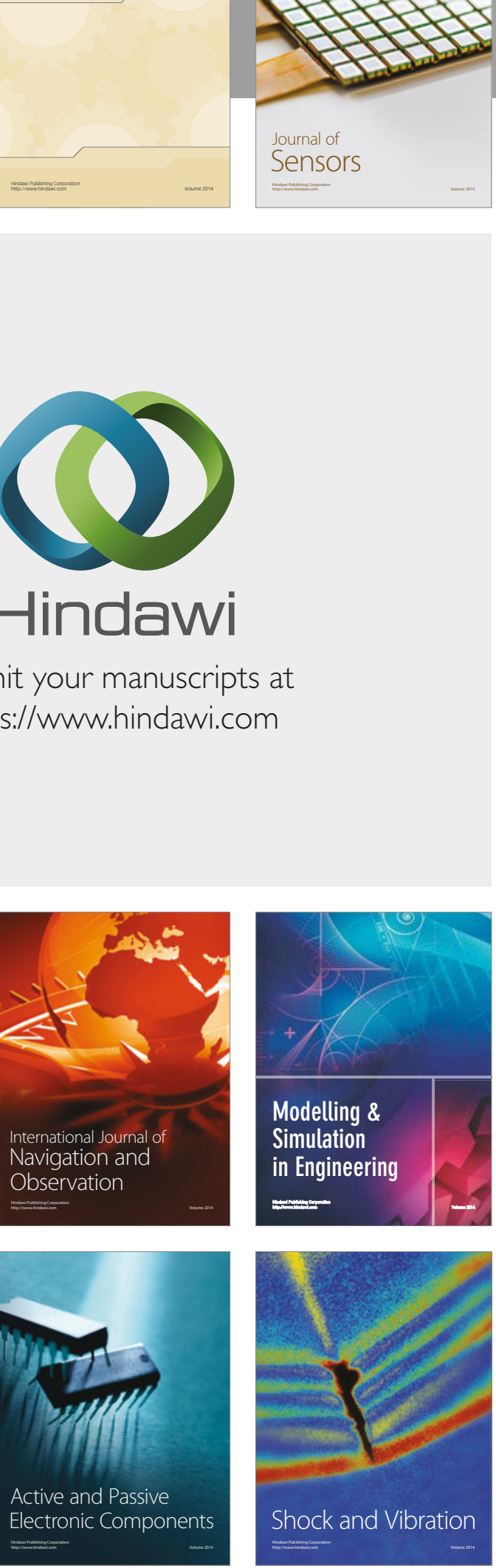
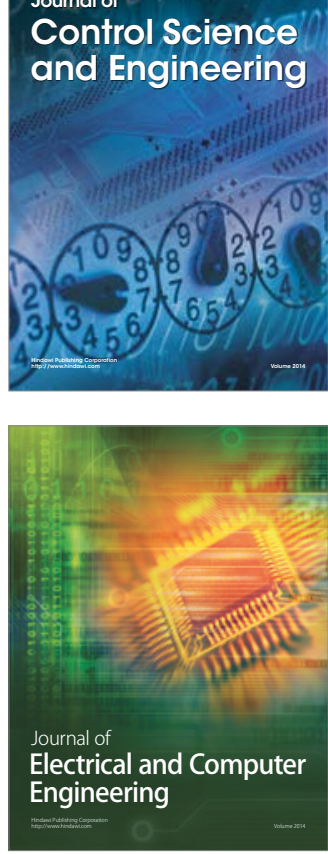

Distributed

Journal of

Control Science

and Engineering
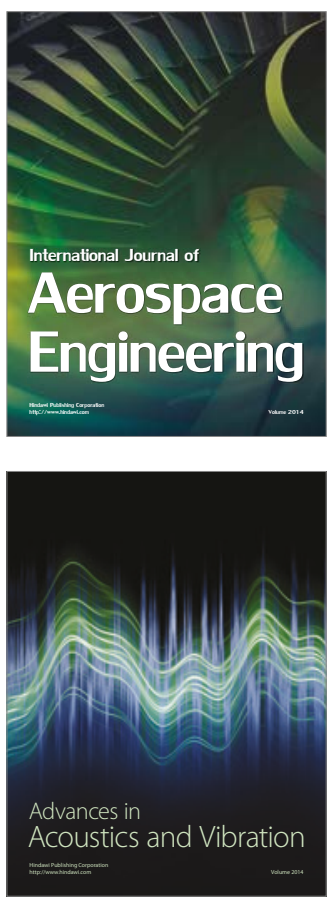

Sensor Networks 